\title{
Association of peripheral and central arterial wave reflections with the CYP11B2 $-344 C$ allele and sodium excretion
}

\author{
Wiktoria Wojciechowska ${ }^{a}$, Jan A. Staessen ${ }^{b}$, Katarzyna Stolarz $^{a}$, Tim Nawrot ${ }^{b}$, \\ Jan Filipovskýc, Milena Tichác ${ }^{\circ}$, Giuseppe Bianchi ${ }^{d}$, Eva Brand ${ }^{\mathrm{e}}$, \\ Marcin Cwynar ${ }^{f}$, Tomasz Grodzickif, Tatiana Kuznetsovab, \\ Harry A. Struijker-Boudierg, Vlasta Svobodovác ${ }^{c}$ Lutgarde Thijs $^{\mathrm{b}}$, \\ Luc M. Van Bortel ${ }^{\mathrm{h}}$ and Kalina Kawecka-Jaszcz ${ }^{\mathrm{a}}$ on behalf of the European \\ Project on Genes in Hypertension (EPOGH) Investigators
}

Objective Angiotensin II and aldosterone, generated by the angiotensin-converting enzyme (ACE) and aldosterone synthase (CYP11B2), respectively, not only regulate sodium and water homeostasis, but also influence vascular remodeling in response to high blood pressure. In the European Project on Genes in Hypertension (EPOGH), we therefore investigated whether the ACE I/D and CYP11B2 C-344T polymorphisms influence early arterial wave reflections, a measure of vascular stiffness.

Methods We measured the peripheral and central augmentation index of systolic blood pressure by applanation tonometry at the level of the radial artery in 622 subjects (160 families and 64 unrelated individuals) randomly recruited from three European populations, whose average urinary sodium excretion ranged from 196 to $245 \mathrm{mmol} /$ day. In multivariate analyses, with sodium excretion analyzed as a continuous variable, we explored the phenotype-genotype associations by means of generalized estimating equations and the quantitative transmission disequilibrium test.

Results The peripheral and central augmentation indexes were significantly higher in CYP11B2 -344C allele carriers than in $-344 T$ homozygotes. In offspring, early wave reflections increased with the transmission of the $-344 C$ allele. This effect of the CYP11B2 polymorphism occurred in subjects with a higher than median urinary sodium excretion ( $210 \mathrm{mmol} / \mathrm{day}$ ). The ACE I/D polymorphism did not influence augmentation of systolic blood pressure.

Conclusions The CYP11B2 C-344T polymorphism affects arterial stiffness. However, sodium intake seems to

\section{Introduction}

The arterial pulse wave consists of a forward and reflected component. The amplitude and velocity of the reflected wave increase with cardiac contractility, a modulate this genetic effect. $J$ Hypertens 22:2311-2319 (C) 2004 Lippincott Williams \& Wilkins.

Journal of Hypertension 2004, 22:2311-2319

Keywords: aldosterone synthase, angiotensin-converting enzyme, augmentation index, genetics, sodium

${ }^{a}$ The First Cardiac Department Medical College, Jagiellonian University, Cracow, Poland, bThe Study Coordinating Centre, Hypertension and Cardiovascular Rehabilitation Unit, Department of Molecular and Cardiovascular Research, University of Leuven, Leuven, Belgium, ${ }^{\mathrm{C}}$ The Department of Internal Medicine II, Charles University Medical School, Pilsen, the Czech Republic, ${ }^{\mathrm{d}}$ The Cattedra e Scuola di Nefrologia, Universitá Vita e Salute San Raffaele, Milano, Italy, ${ }^{\mathrm{e}}$ The Department of Internal Medicine D (Nephrology), University of Munster, Germany, fThe Department of Internal Medicine and Gerontology Medical College, Jagiellonian University, Cracow, Poland, ${ }^{9}$ The Department of Pharmacology and Toxicology, Cardiovascular Research Institute, University of Maastricht, Maastricht, The Netherlands and ${ }^{\mathrm{h}}$ The Division of Clinical Pharmacology and Pharmacotherapy, Heymans Institute for Pharmacology, University of Ghent, Ghent, Belgium.

Sponsorship: Nuclear families were recruited in the framework of the European Project on Genes in Hypertension, which was supported by the European Union (contract numbers IC15-CT98-0329-EPOGH and QLGI-CT-2000-01137-

EURNETGEN). The study was also supported by research grant G.0424.03 from the Fonds voor Wetenschappelijk Onderzoek Vlaanderen (Brussels, Belgium), by a special research grant (Onderzoekstoelage OT/99 per 28) from the Katholieke Universiteit Leuven (Leuven, Belgium), by research grants (OK 375 and OK 376) from the Czech Ministry of Education, and by the International Scientific and Technological Cooperation between Poland and Flanders (contract number BIL 00/18). E. B. participated in the research programme Innovationen des Therapiekonzeptes für das metabolische Syndrom - mit Fokus auf Hypertonie' (PTJ-BIO/0313040C), funded by the Bundesministerium für Bildung und Forschung (Berlin, Germany).

Correspondence and requests for reprints to Jan A. Staessen, Study Coordinating Centre, Laboratory of Hypertension, Hypertension and

Cardiovascular Rehabilitation Unit, Department of Molecular and Cardiovascular Research, Campus Gasthuisberg, University of Leuven, Herestraat 49, B-3000 Leuven, Belgium.

Tel: +32 1634 7104; fax: +32 1634 7106;

e-mail: jan.staessen@med.kuleuven.ac.be

Received 20 February 2004 Revised 3 June 2004 Accepted 15 July 2004

more proximal localization of the sites of reflection along the arterial tree and arterial stiffness. The augmentation index, derived from the pulse contour, reflects the degree to which reflected waves enhance 
systolic pressure [1]. Twin studies recently demonstrated that independent of blood pressure, heart rate, height, and age, the heritability of the aortic augmentation index was $37 \%$ [2].

Angiotensin II and aldosterone play key roles in the regulation of sodium and water homeostasis. In sodium deplete conditions, these hormones are upregulated, whereas the opposite occurs in the presence of a high salt intake. Circulating angiotensin II is produced by cleavage of angiotensin I by the angiotensin-converting enzyme (ACE) at the endothelial-luminal interface throughout the vasculature, in particular in the pulmonary circulation. Carriers of the $A C E$ deletion polymorphism have constitutively increased plasma and tissue levels of ACE [3]. Aldosterone is generated in the adrenal gland by aldosterone synthase (CYP11B2). However, both angiotensin II and aldosterone are also locally produced in the arterial wall, influence vascular structure and function, and mediate vascular remodeling in response to pathological stimuli, such as a high blood pressure $[4,5]$.

In the European Project on Genes in Hypertension (EPOGH), we investigated whether the $A C E I / D$ and CYP11B2 C-344T polymorphisms impact on the peripheral and central augmentation indexes, as assessed by applanation tonometry at the level of the radial artery. Our analyses accounted for salt intake, estimated from the urinary excretion of sodium and for other host and environmental determinants of cardiovascular function.

\section{Methods}

\section{Study population}

The European Project on Genes in Hypertension (EPOGH) was conducted according to the principles outlined in the Helsinki declaration for investigations in human subjects. The Ethics Committee of each institution approved the protocol. Participants gave informed written consent.

Three EPOGH centers opted to take part in vascular phenotyping. They randomly recruited nuclear families of Caucasian extraction, including offspring with a minimum age of 10 years in Belgium and 18 years in the two other countries. Overall, the response rate was $82 \%$. Of 870 participants recruited in Cracow (Poland, $n=302$ ), Hechtel-Eksel (Belgium, $n=380$ ) and Pilsen (Czech Republic, $n=188$ ), we discarded 21 from analysis because the recorded pulse wave was of insufficient quality and 60 because of missing genotypes. In addition, we detected six cases of inconsistency in Mendelian segregation. The Belgian sample included seven extended families spanning more than two generations. Because there is no generally agreed algorithm to construct the variance-covariance matrix for correlated data within extended pedigrees using generalized esti- mating equations (see below), we selected from each complex family the most informative nuclear unit with the largest number of phenotypes and genotypes. This procedure removed 161 Belgian subjects from our analyses. Thus, the overall number of participants analyzed statistically totaled 622 .

\section{Phenotypes and genotypes}

After subjects had rested for $15 \mathrm{~min}$, we recorded, during an 8-s period, the radial arterial waveform at the dominant arm by applanation tonometry. We used a high-fidelity SPC-301 micromanometer (Millar Instruments, Inc., Houston, Texas, USA) interfaced with a laptop computer running SphygmoCor software, version 6.31 (AtCor Medical Pty. Ltd., West Ryde, New South Wales, Australia). We discarded recordings when the systolic or diastolic variability of consecutive waveforms exceeded $5 \%$ or when the amplitude of the pulse wave signal was less than $80 \mathrm{mV}$. We calibrated the pulse wave by measuring blood pressure at the contralateral arm immediately before the recordings. From the radial signal, the SphygmoCor software calculates the aortic pulse wave by means of a validated and populationbased generalized transfer function [6]. The radial augmentation index was defined as the ratio of the second to the first peak of the pressure wave expressed as a percentage. The aortic augmentation index was the difference between the second and first systolic peak given as a percentage of the aortic pulse pressure. For statistical analysis, we used the average of the peripheral and central waveforms over the 8-s measurement period.

The blood pressure phenotype was the average of five consecutive readings obtained at one home visit. Peripheral and central pulse pressures were defined as the difference between systolic and diastolic blood pressure derived from the brachial blood pressure measured at the subjects homes and from the aortic pulse wave, respectively. From the home readings, we calculated mean arterial pressure as the diastolic pressure plus one-third of peripheral pulse pressure. We administered a standardized questionnaire to obtain information on each subject's medical history, smoking and drinking habits and use of medications. The participants collected a 24-h urine sample in a wide-neck plastic container for the measurement of sodium, potassium, creatinine and aldosterone. For statistical analysis of the urinary phenotypes, we excluded 18 subjects because according to previously published criteria [7] the urine samples were judged to be under- or overcollected. Genomic DNA from white blood cells was amplified and genotyped for the $A C E I / D$ and $C Y P 11 B 2$ $C-344 T$ polymorphisms, as previously described [8,9]. For the $A C E$ gene, all samples initially genotyped as $D D$ underwent a second polymerization chain reaction with insertion-specific primers. 


\section{Statistical methods}

Database management and most statistical analyses were performed with SAS software version 8.1 (SAS Institute Inc., Cary, North Carolina, USA). Population means and proportions were compared by Tukey's multiple means test and the $\chi^{2}$ statistic with Bonferroni's adjustment for multiple comparisons, respectively. If Shapiro-Wilk's test showed significant departure from normality, we analyzed logarithmically transformed variables. We searched for possible covariates of the augmentation indexes using stepwise multiple regression with the $P$ value for independent variables to enter and stay in the model set at 0.10 . We used the methods described by Kleinbaum et al. [10] to test the null hypothesis of no differences between the parameters of regression equations.

We performed population-based as well as family-based analyses. In the population-based approach, we tested association of continuous traits with the genotypes of interest by use of generalized estimating equations (GEE). This approach allows adjustment for covariates as well as for the non-independence of observations within families [11]. In GEE, we also tested for heterogeneity between populations, using appropriate interaction terms with the genotypes.

In the family-based analyses, we performed transmission disequilibrium tests for quantitative traits (QTDT) using two different methods. First, we evaluated the within- and between-family components of phenotypic variance, using the orthogonal model as implemented by Abecasis et al. in the QTDT software, version 2.3 (http://www.sph.umich.edu/csq/abecasis/QTDT) [12]. In addition, using the model proposed by Allison, we regressed the quantitative phenotypes of informative offspring on their genotypes, while controlling for parental genotypes [13]. To allow for residual correlation among offspring, we implemented Allison's model using GEE.

\section{Results}

\section{Characteristics of participants}

Table 1 gives the characteristics of the participants by country. Overall, the study population included 558 subjects from 160 nuclear families and 64 unrelated individuals. Mean ( \pm SD) age of the 294 founders and 328 offspring was $51.7 \pm 8.5$ and $29.9 \pm 10.6$ years, respectively. The number of sibs per family amounted to one in 34 families, two in 102 families, and ranged from three to eight in 24 families. The Belgian participants were older than the subjects from the two other countries. Compared with Polish participants, fewer Belgians were on antihypertensive drug treatment. Czechs more frequently reported regular alcohol intake ( $\geqslant 5 \mathrm{~g} /$ day) than Belgians and Polish. Urinary sodium excretion was on average 50 and $36 \mathrm{mmol} / \mathrm{day}$ higher in Poland than in Belgium and Czechia, respectively. The urinary aldosterone excretion was lower in Poland than in the other two countries. Figure 1 shows the sex and age dependence of the peripheral and central augmentation indexes, which in the whole study population averaged $68.0 \pm 23.1$ and $16.4 \pm 17.1 \%$, respectively. As shown in Figure 2, systolic pressure in

Table 1 Characteristics of the study participants by country

\begin{tabular}{|c|c|c|c|}
\hline & Belgium & Czechia & Poland \\
\hline No. & 181 & 147 & 294 \\
\hline \multicolumn{4}{|l|}{ Anthropometrical characteristics } \\
\hline Age (years) & $46.8 \pm 14.6$ & $37.9 \pm 13.5^{\star}$ & $37.2 \pm 13.9^{*}$ \\
\hline Female gender (\%) & 57.5 & 57.1 & 53.4 \\
\hline Height $(\mathrm{cm})$ & $167.4 \pm 9.4$ & $171.1 \pm 9.1^{*}$ & $169.9 \pm 8.7^{\star}$ \\
\hline Weight (kg) & $72.2 \pm 14.5$ & $76.7 \pm 16.1^{\star}$ & $73.3 \pm 14.4$ \\
\hline \multicolumn{4}{|l|}{ Hemodynamic measurements } \\
\hline Systolic pressure $(\mathrm{mmHg}) \dagger$ & $125.0 \pm 15.7^{\star \star \star}$ & $123.8 \pm 16.6^{\star \star \star}$ & $128.8 \pm 17.5$ \\
\hline Diastolic pressure $(\mathrm{mmHg}) \dagger$ & $78.6 \pm 11.4$ & $77.8 \pm 10.9$ & $80.3 \pm 12.2$ \\
\hline Peripheral augmentation index (\%) & $72.7 \pm 21.9$ & $63.7 \pm 23.7^{\star}$ & $67.3 \pm 23.0^{*}$ \\
\hline Central augmentation index (\%) & $21.2 \pm 15.5$ & $14.0 \pm 17.9^{*}$ & $14.6 \pm 17.1^{*}$ \\
\hline Pulse rate (beats/min) & $62.8 \pm 9.4^{\star \star \star}$ & $67.0 \pm 9.7^{\star}$ & $73.3 \pm 11.4^{\star \star}$ \\
\hline \multicolumn{4}{|l|}{ Questionnaire data } \\
\hline Antihypertensive treatment $(\%)$ & 12.7 & 21.1 & $23.8^{\star}$ \\
\hline Current smokers (\%) & 28.2 & 25.8 & 27.6 \\
\hline Regular alcohol intake (\%) & 27.1 & $45.6^{*}$ & $19.1^{\mathrm{C}}$ \\
\hline \multicolumn{4}{|l|}{ Urinary excretion } \\
\hline Volume (I/day)‡ & $1.64 \pm 0.77^{\star \star *}$ & $1.93 \pm 0.67^{\star}$ & $1.45 \pm 0.53^{\star \star}$ \\
\hline Sodium (mmol/day) & $196 \pm 65^{\star \star \star}$ & $210 \pm 83$ & $245 \pm 87^{\star \star}$ \\
\hline Potassium (mmol/day) & $70 \pm 27$ & $62 \pm 29^{\star}$ & $65 \pm 25$ \\
\hline Aldosterone (nmol/day) & $20.0(17.4-22.9)^{\star * *}$ & $17.4(15.8-19.1)$ & $10.7(9.8-11.7)^{\star \star}$ \\
\hline Creatinine (mmol/day) & $10.7 \pm 3.5^{\star \star \star}$ & $13.3 \pm 4.1^{*}$ & $12.1 \pm 4.1^{\star *}$ \\
\hline
\end{tabular}

Values are arithmetic means $\pm \mathrm{SD}$, geometric means (95\% confidence interval) or the percentage of subjects. $P$ values for between-country differences were adjusted for multiple comparisons by Tukey's test (means) or Bonferroni's method (proportions): ${ }^{*} P \leqslant 0.05$ versus Belgium; ${ }^{* *} P \leqslant 0.05$ versus Czechia; ${ }^{* \star} P \leqslant 0.05$ versus Poland. tAverage of five readings obtained at one home visit. ₹The number of subjects with $24 \mathrm{~h}$ collection was 181 in Belgium, 133 in Czechia and 290 in Poland. 
Fig. 1



Peripheral and central augmentation indexes by sex and age class. Values are non-adjusted means $\pm \mathrm{SE}$. The number of subjects contributing to each mean is given.

Fig. 2

Brachial and radial arteries

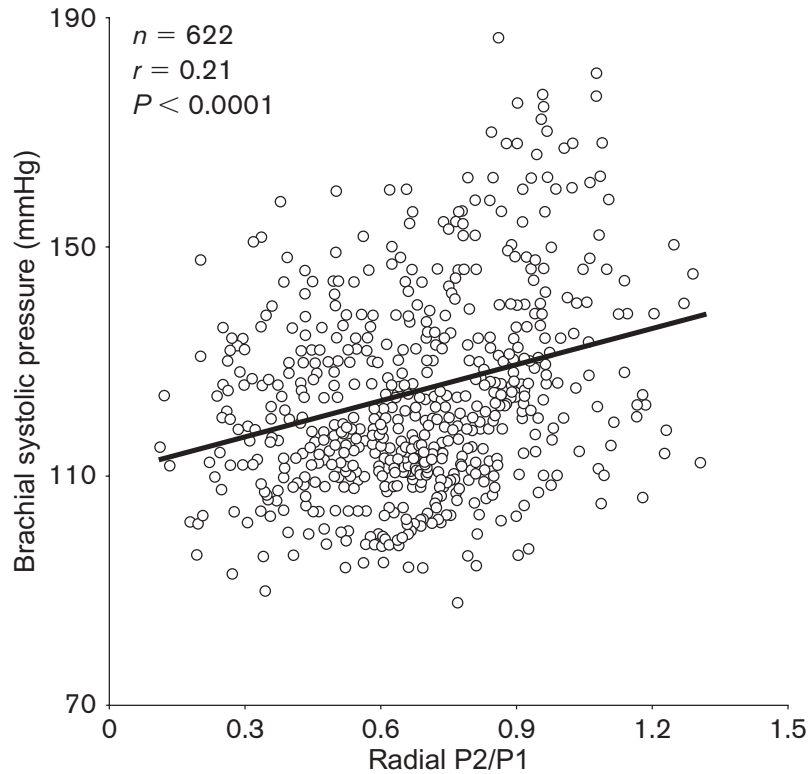

Aorta

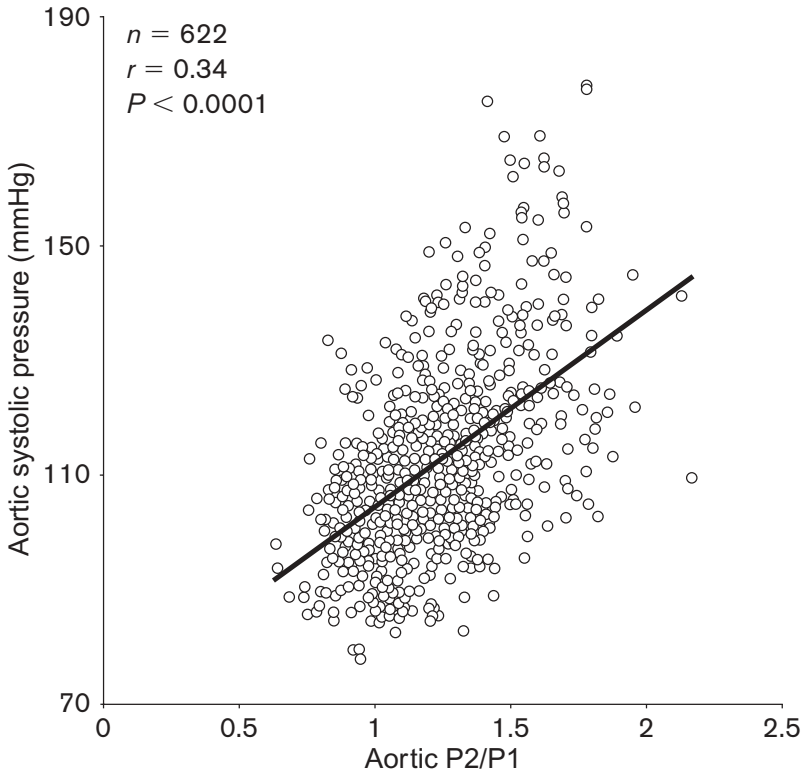

Local systolic pressure in the brachial and radial arteries and in the aorta in relation to systolic augmentation calculated as a the ratio of the second (P2) to the first (P1) systolic peak. The aortic measurements were extrapolated from the radial waveform by means of the SphygmoCor software. 
the brachial artery and aorta significantly $(P<0.0001)$ increased with the ratio of the second to the first systolic peak. Furthermore, the slope of systolic blood pressure on this ratio was significantly $(P=0.0002)$ steeper in the aorta than in the radial artery.

Stepwise multiple regression demonstrated that the peripheral augmentation index significantly and independently increased with female gender (regression coefficient $\beta \pm \mathrm{SE} ; 9.16 \pm 1.58 \% ; \quad P=0.0001)$, age $(0.81 \pm 0.04 \%$ per year; $P=0.0001)$, mean arterial pressure $(0.38 \pm 0.05 \%$ per $\mathrm{mmHg} ; \quad P=0.0001)$, current smoking $(5.20 \pm 1.20 \% ; \quad P=0.0001)$, whereas it decreased with body height $(-0.52 \pm 0.09 \%$ per $\mathrm{cm}$; $P=0.0001)$ and pulse rate $(-0.63 \pm 0.05 \%$ per beat; $P=0.0001)$. Similarly, the central augmentation index increased with female gender $(6.80 \pm 1.17 \% ; \quad P=$ $0.0001)$, age $(0.61 \pm 0.03 \%$ per year; $P=0.0014)$, mean arterial pressure $(0.26 \pm 0.04 \%$ per $\mathrm{mmHg} ; P=0.0001)$, current smoking $(2.94 \pm 0.92 \% ; P=0.0001)$, whereas it decreased with body height $(-0.38 \pm 0.07 \%$ per $\mathrm{cm}$; $P=0.0001)$, pulse rate $(-0.50 \pm 0.04 \%$ per beat; $P=0.0001)$ and current antihypertensive treatment $(-2.10 \pm 1.17 \% ; \quad P=0.07)$. We adjusted all further analyses for the aforementioned covariates as well as for observer (one in Belgium, one in Czechia, and two in Poland). Further analyses also accounted for sodium intake estimated from the 24-h urinary excretion.

The within-country frequencies of genotypes (Table 2) complied with Hardy-Weinberg equilibrium $(0.36 \leqslant$ $P \leqslant 0.94)$. The genotype and allele frequencies were similar across countries for the $A C E$ gene. The CYP11B2 $-344 C$ allele was more prevalent in Poland than Belgium.

Both before and after adjustment for urinary sodium and potassium, the 24-h urinary aldosterone excretion was not associated with the CYP11B2 C-344T polymorphism $(P \geqslant 0.16)$. In all countries, aldosterone excretion adjusted for sex and age was closely correlated with urinary sodium and potassium. With additional adjustment for country, the overall partial correlation coefficients were -0.11 for sodium, 0.30 for potassium and -0.38 for the urinary sodium-to-potassium ratio $(P<0.01$, for all $)$.

\section{Population-based association study}

Because across centers there was no heterogeneity in the phenotype-genotype relations $(0.07 \leqslant P \leqslant 0.82)$, we combined all countries. Furthermore, for none of the phenotype-genotype relations, we found significant interactions with gender $(0.54 \leqslant P \leqslant 0.94)$ or generation (parents versus offspring; $0.39 \leqslant P \leqslant 0.80$ ).

GEE did not reveal any association between the augmentation indexes and the $A C E I / D$ polymorphism. In the whole study population as well as in offspring, the peripheral and central augmentation indexes were significantly higher in the CYP11B2 $-344 C$ allele carriers than in the $-344 T T$ homozygotes with similar trends in founders (Table 3). Further analyses (Table 4) demonstrated that in founders central, but not peripheral, pulse pressure was also significantly higher in CYP11B2-344C allele carriers than in -344TT homozygotes. There was no interaction between the $A C E$ and CYP11B2 genotypes $(P>0.22)$. However, in untreated subjects $(n=483)$, we observed a significant interaction between the CYP11B2 genotype and sodium excretion, analyzed as a continuous variable, in relation to the peripheral $(P=0.029)$ and central $(P=0.013)$ augmentation indexes. Figure 3 illustrates these interactions according to the country- and sex-specific median of sodium excretion (approximately $210 \mathrm{mmol} /$ day).

\section{Family-based association study}

With the exception of the $A C E$ gene in Czechia $(P<0.01)$, Abecasis' orthogonal model did not reveal population stratification in any country $(0.19 \leqslant P \leqslant$ 0.34). In 216 informative offspring, it confirmed significant association between the peripheral augmentation index and the transmission of the CYP11B2 -344C allele (effect size, $+3.0 \% ; P=0.028$ ) with a similar trend for the central augmentation index (effect size, $+2.2 \% ; P=0.092)$. Using Allison's approach, the

\begin{tabular}{|c|c|c|c|c|c|c|}
\hline \multirow{2}{*}{$\frac{\text { Gene }}{\text { ACE }}$} & \multirow[t]{2}{*}{ Country } & \multicolumn{2}{|c|}{ Allele } & \multicolumn{3}{|c|}{ Genotypes } \\
\hline & & $\mathrm{D}$ & I & DD & DI & II \\
\hline & Czechia & $158(53.7)$ & $136(46.3)$ & $40(27.2)$ & $78(53.1)$ & 29 (19.7) \\
\hline & Poland & $302(51.4)$ & $286(48.6)$ & $72(24.5)$ & $158(53.7)$ & $64(21.8)$ \\
\hline & Belgium & $184(50.8)$ & $178(49.2)$ & $49(27.1)$ & $86(47.5)$ & $46(25.4)$ \\
\hline \multirow{4}{*}{ CYP11B2 } & & $\mathrm{T}$ & $\mathrm{C}$ & TT & $\mathrm{TC}$ & $\mathrm{CC}$ \\
\hline & Belgium & $216(59.7)$ & $146(40.3)$ & $63(34.8)$ & $90(49.7)$ & $28(15.5)$ \\
\hline & Czechia & $172(58.5)$ & $122(41.5)$ & $50(34.0)$ & $72(49.0)$ & $25(17.0)$ \\
\hline & Poland & $297(50.5)$ & $291(49.5)$ & $70(23.8)$ & $157(53.4)$ & $67(22.8)$ \\
\hline
\end{tabular}

Values indicate number of alleles or genotypes (\%). Braces join countries with similar allele frequencies. ACE, angiotensin-converting enzyme. 
Table 3 Peripheral and central augmentation indexes by genotypes in nuclear families

\begin{tabular}{|c|c|c|c|c|c|c|c|}
\hline \multirow{2}{*}{$\frac{\text { Gene }}{\mathrm{ACE}}$} & \multicolumn{2}{|c|}{ Augmentation index } & \multirow{2}{*}{$\begin{array}{c}n \\
\mathrm{DD} / \mathrm{DI} / \mathrm{I}\end{array}$} & \multicolumn{3}{|c|}{ Adjusted mean \pm SE $†$} & \multirow[b]{2}{*}{$P^{*}$} \\
\hline & & & & DD & DI & ॥ & \\
\hline & Peripheral & All & $161 / 322 / 139$ & $68.4 \pm 1.0$ & $68.1 \pm 0.8$ & $67.9 \pm 1.3$ & 0.79 \\
\hline & & Founders & 79/156/59 & $80.4 \pm 1.5$ & $81.5 \pm 1.1$ & $81.1 \pm 1.9$ & 0.58 \\
\hline & & Offspring & $82 / 166 / 80$ & $57.3 \pm 1.3$ & $56.2 \pm 1.1$ & $55.6 \pm 1.5$ & 0.39 \\
\hline & Central & All & $161 / 322 / 139$ & $17.1 \pm 0.8$ & $16.1 \pm 0.6$ & $16.5 \pm 1.0$ & 0.35 \\
\hline & & Founders & 79/156/59 & $25.9 \pm 1.0$ & $25.7 \pm 0.7$ & $25.6 \pm 1.3$ & 0.85 \\
\hline & & Offspring & $82 / 166 / 80$ & $9.3 \pm 1.2$ & $7.6 \pm 0.9$ & $7.7 \pm 1.2$ & 0.24 \\
\hline \multirow[t]{7}{*}{ CYP11B2 } & & & $\mathrm{TT} / \mathrm{TC} / \mathrm{CC}$ & $\mathrm{TT}$ & TC & $\mathrm{CC}$ & $P^{\star \star}$ \\
\hline & Peripheral & All & $183 / 319 / 120$ & $66.1 \pm 1.1$ & $68.8 \pm 0.9$ & $69.5 \pm 1.1$ & 0.027 \\
\hline & & Founders & $84 / 155 / 55$ & $79.3 \pm 1.5$ & $81.3 \pm 1.2$ & $83.3 \pm 1.4$ & 0.16 \\
\hline & & Offspring & $99 / 164 / 65$ & $53.1 \pm 1.4$ & $57.9 \pm 1.0$ & $57.4 \pm 1.6$ & 0.004 \\
\hline & Central & All & $183 / 319 / 120$ & $15.1 \pm 0.8$ & $16.8 \pm 0.6$ & $17.6 \pm 0.9$ & 0.050 \\
\hline & & Founders & $84 / 155 / 55$ & $24.4 \pm 1.0$ & $25.8 \pm 0.7$ & $27.6 \pm 1.1$ & 0.12 \\
\hline & & Offspring & $99 / 164 / 65$ & $6.2 \pm 1.2$ & $9.1 \pm 0.8$ & $8.4 \pm 1.5$ & 0.049 \\
\hline
\end{tabular}

†Adjustments included: observer, sex, age, body height, pulse rate, mean arterial pressure, current smoking and antihypertensive treatment. ${ }^{\star} P$ value for comparison between $A C E D D$ versus $D I+I I .{ }^{* *} P$ value for comparison between $C Y P 11 B 2 T T$ versus $T C+C C$. ACE, angiotensin-converting enzyme.

Table 4 Peripheral and central pulse pressure in relation to the CYP11B2 genotype

\begin{tabular}{|c|c|c|c|c|c|c|}
\hline \multirow[b]{2}{*}{ Pulse pressure } & & \multirow{2}{*}{$\begin{array}{c}n \\
(\mathrm{CC} / \mathrm{TC} / \mathrm{TT})\end{array}$} & \multicolumn{3}{|c|}{ Adjusted mean \pm SE $\dagger$} & \multirow[b]{2}{*}{$P^{\star}$} \\
\hline & & & 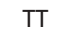 & TC & $\mathrm{CC}$ & \\
\hline \multirow{3}{*}{ Peripheral } & All & $161 / 322 / 139$ & 47.9 & 47.5 & 46.8 & 0.53 \\
\hline & Founders & 79/156/59 & 49.6 & 49.4 & 48.8 & 0.84 \\
\hline & Offspring & $82 / 166 / 80$ & 46.1 & 44.9 & 45.7 & 0.45 \\
\hline \multirow[t]{3}{*}{ Central } & All & $161 / 322 / 139$ & 31.9 & 33.4 & 32.9 & 0.06 \\
\hline & Founders & $79 / 156 / 59$ & 34.8 & 38.4 & 36.4 & 0.01 \\
\hline & Offspring & $82 / 166 / 80$ & 29.2 & 28.8 & 29.5 & 0.75 \\
\hline
\end{tabular}

†Pulse pressure was adjusted for sex, age, body height, pulse rate, current smoking and antihypertensive treatment. Additional adjustments included observer and mean arterial pressure for the central pulse pressure and country for the peripheral pulse pressure. ${ }^{*} P$ value for comparison between CYP11B2 TT versus $T C+C C$.

number of informative offspring decreased to 135 , but the test statistic remained significant for the association between the peripheral augmentation index and the CYP11B2 polymorphism with a similar tendency for the central augmentation index (Table 5). None of the QTDT models provided any evidence for association between the pulse wave phenotypes and transmission of the $A C E D$ allele.

\section{Discussion}

The main finding of our study was that in both population-based and family-based analyses, early arterial wave reflections increased with the presence or transmission of the CYP11B2 $-344 C$ allele. This genetic effect was more pronounced in subjects whose sodium excretion exceeded $210 \mathrm{mmol} /$ day. The frequency of the $-344 T$ allele was higher in Belgians $(60 \%)$ than Polish $(51 \%)$. However, this difference in allele frequency did not impact on our results. Indeed, we neither observed heterogeneity in the phenotypegenotype relation across countries nor stratification within any population. Previous studies reported CYP11B2 -344T allele frequencies of $45 \%$ [14] in Caucasians and 64\% [15] in Japanese.
Aldosterone synthase is a cytochrome P450 enzyme and catalyzes the terminal steps in aldosterone biosyntheses. Chromosome 8 harbors the human gene. The $C$ $344 T$ polymorphism is located in an enhancer element, which is also present in the genes of other adrenal hydroxylases [16] and interacts with the regulatory protein steroidogenic factor (SF-1) [17]. Several in vitro studies addressed the possible functional role of CYP11B2 [17-20]. Preliminary gel-shift experiments suggested that on a molar basis the $C$ compared with the $T$ containing element bound SF-1 about four times more effectively [18]. Subsequent transfection studies of human adrenocortical cells showed that the $C-344 T$ locus is not essential for basal or regulated expression of human CYP11B2, apparently because the human gene contains an additional SF-1 binding site closer to the start of transcription [17,19]. However, these experiments do not exclude a functional role of the $C$ $344 T$ polymorphism, because GYP11B2 is expressed in cardiac [21] and vascular [5,21] tissue and because its expression might be differentially regulated in steroidogenic and non-steroidogenic tissues [20].

Within and across populations, we did not find any 
Fig. 3

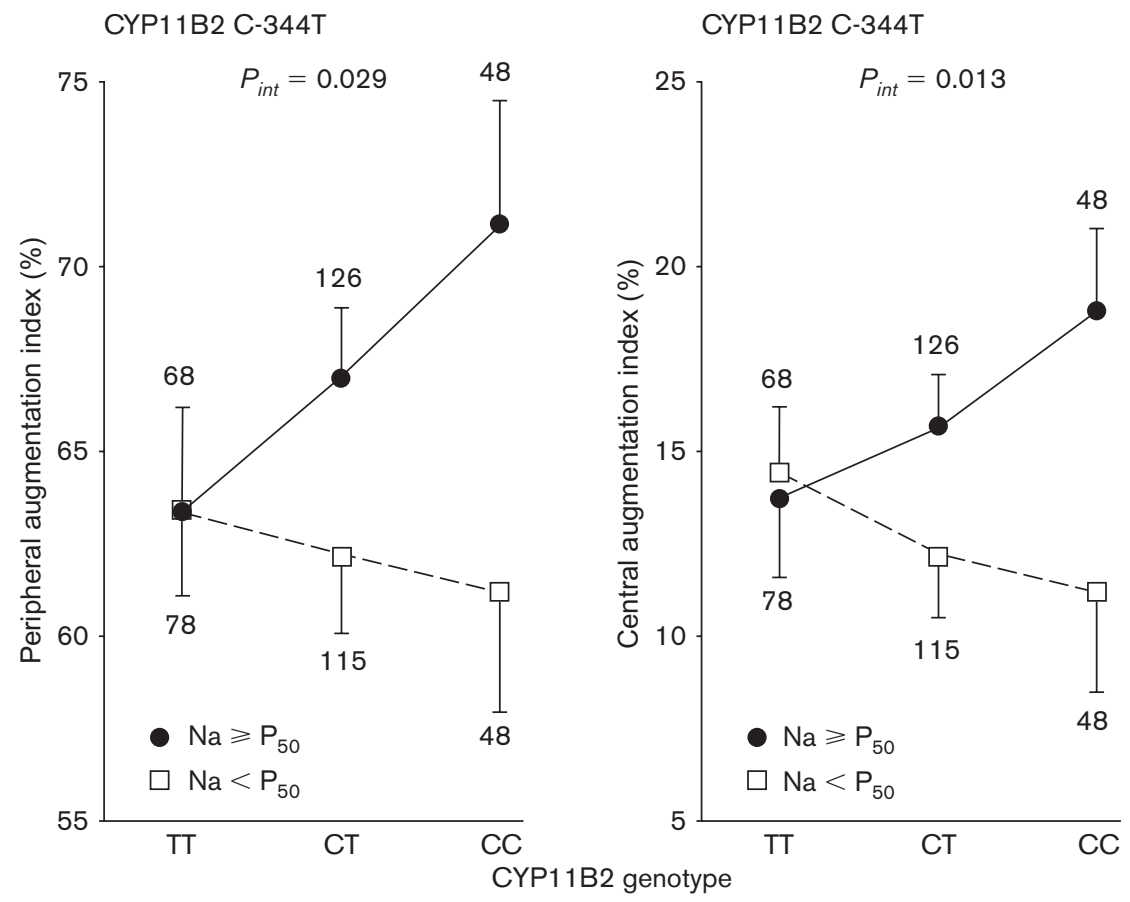

Peripheral and central augmentation indexes by CYP11B2 genotype and median sodium excretion ( 210 mmol/day) in 483 untreated subjects. Values are adjusted means $\pm \mathrm{SE}$. The significance of the genotype-by-sodium interaction $\left(P_{\text {int }}\right)$ was derived from a generalized estimating equations (GEE) model, which included sodium excretion as a continuous variable and which accounted for clustering within families and significant covariates (Table 3).

Table 5 QTDT analyses of peripheral and central augmentation indexes

\begin{tabular}{|c|c|c|c|c|c|c|c|}
\hline \multirow[b]{2}{*}{ Gene } & \multirow{2}{*}{$\begin{array}{l}\text { Number of offspring } \\
\text { informative/all }\end{array}$} & \multicolumn{3}{|c|}{ Peripheral augmentation index } & \multicolumn{3}{|c|}{ Central augmentation index } \\
\hline & & $\beta(\%)$ & $\chi^{2}$ & $P$ & $\beta(\%)$ & $\chi^{2}$ & $P$ \\
\hline \multicolumn{8}{|l|}{ ACE } \\
\hline Orthogonal model & $212 / 328$ & +1.7 & 1.51 & 0.22 & +1.8 & 2.21 & 0.14 \\
\hline Allison's model & $137 / 328$ & +2.4 & 0.77 & 0.37 & +3.0 & 1.70 & 0.19 \\
\hline \multicolumn{8}{|l|}{ CYP11B2 } \\
\hline Orthogonal model & $216 / 328$ & +3.0 & 4.84 & 0.028 & +2.2 & 2.83 & 0.092 \\
\hline Allison's model & $135 / 328$ & +7.2 & 4.61 & 0.031 & +4.3 & 2.94 & 0.086 \\
\hline
\end{tabular}

The orthogonal model accounted for between- and within-family components of phenotypic variability. The parameter estimate $(\beta)$ for the within-family variability component indicates the direction and size of the association when the ACE $D$ allele or the CYP11B2 -344C allele were transmitted. Adjustments were similar as in Table 3. ACE, angiotensin-converting enzyme.

relation between the urinary aldosterone excretion and the CYP11B2 G-344T polymorphism. Other studies on the putative association between plasma or urinary aldosterone and genetic variation in the CYP11B2 gene produced inconsistent results. Indeed, they showed higher plasma levels of aldosterone associated with the $-344 C$ [22] or $-344 T$ allele [23], higher urinary aldosterone excretion in the presence of the $-344 T$ allele $[24,25]$ and divergent results for blood pressure analyzed as a binary or continuous phenotype $[14,15,22,24-26]$. In the light of our present findings, the contradiction in the literature is not surprising, because few studies accounted for sodium intake, which is an important determinant of aldosterone production. We noticed a major interaction between the CYP11B2 C-344T polymorphism and sodium excretion in relation to a vascular phenotype.

Arterial stiffness and the velocity and amplitude of reflected arterial waves are the main determinants of the peripheral and central augmentation indexes. In keeping with current physiological concepts [27], we found that the augmentation of systolic pressure was significantly higher in the aorta compared with the 
brachial artery. Wave reflections occur at sites of changes of arterial impedance along the arterial tree, such as branching points or atherosclerotic plaques. However, in the present study, we adjusted the augmentation indexes for body height and pulse rate, so that to a large extent these phenotypes probably reflected vascular stiffness rather than changes in the localization of the reflection points. In keeping with our present observations, some researchers reported a positive association of the CYP11B2 $-344 C$ allele with arterial stiffness [22] or with the prevalence [15] or incidence [26] of hypertension. However, the physiological and molecular pathways via which this polymorphism might impact on vascular stiffness remain to be elucidated.

Blacher and coworkers noticed in hypertensive patients $(r=-0.497 ; P<0.01)$, but not normotensive subjects, a close and inverse correlation between systemic arterial compliance and the plasma aldosterone concentration [28]. The absence of a direct relation between vascular stiffness and plasma aldosterone in our study $(P>0.25)$ and other reports $[26,28]$ might be explained by the local generation of aldosterone in the endothelium or in vascular smooth muscle cells [5]. Indeed, in rats, the concentration of aldosterone in cardiac tissue was 17-fold higher than in plasma [21].

We observed a significant interaction between the CYP11B2 C-344T polymorphism and sodium excretion, analyzed as a continuous variable, in relation to the peripheral and central augmentation of systolic blood pressure. Previous studies demonstrated that in humans a high salt intake is associated with increased arterial stiffness and vascular and cardiac hypertrophy [29]. Furthermore, in normotensive Wistar-Kyoto rats, a high salt diet $(0.9 \% \mathrm{NaCl})$ stimulated the expression of mRNA for CYP11B2 in the myocardium [30]. Sodium loading activated local aldosterone synthesis with elevated tissue levels of the steroid and produced cardiac hypertrophy in the absence of a noticeable increase in blood pressure [30]. Similarly, stroke-prone spontaneously hypertensive rats fed $0.9 \% \mathrm{NaCl}$ in drinking water, compared with the control group given tap water, had increased expression of mRNA for CYP11B2 in the arterial wall, but lower levels of circulating aldosterone [31]. Thus, an excessive salt intake might contribute to increased arterial stiffness by inappropriately sustaining the expression of the CYP11B2 gene in the arterial wall, despite a decrease of the angiotensin II and aldosterone levels in the blood.

Because plasma and tissue levels of ACE increase with the number of copies of the ACE $D$ allele [3] and because angiotensin II is a potent vasoconstrictor and stimulates vascular growth, the hypothesis that the $A C E$ deletion polymorphism might be associated with in- creased vascular stiffness is plausible. However, in keeping with the contradictory results of previous studies [32,33], we did not observe such a relation. Our null findings with respect to the $A C E I / D$ polymorphism might be due to the plasticity of the renin-angiotensin system, as exemplified by the multiple pathways via which angiotensin II can be generated, or to the activation by angiotensin II of counter-regulatory hormonal or paracrine mechanisms [4].

The present study has to be interpreted within the context of its limitations and strengths. One 24-h urine collection is insufficient to characterize an individual's habitual sodium intake, but it does accurately reflect the average salt consumption of groups of subjects [34]. We investigated the interaction between the CYP11B2 polymorphism and sodium excretion in relation to augmentation of systolic pressure only in untreated subjects, because many antihypertensive drugs, in particular diuretics, influence renal sodium handling. There was consistency between the population-based and family-based statistical approaches and between the results involving the central and peripheral augmentation indexes. The latter was obtained directly from the radial pulse wave and did not involve extrapolation based on the transfer function implemented in the SphygmoCor software.

In conclusion, our study suggests that a common variant of the CYP11B2 gene, located in the promoter area, may be involved in the pathophysiology of arterial stiffness. However, sodium intake seems to modulate this genetic effect.

\section{Acknowledgements}

This study would not have been possible without the voluntary collaboration of the participants. Professor Michael F. O'Rourke (Saint Vincent's Hospital, Darlinghurst, Sydney, Australia) helped with the interpretation of the SphygmoCor data. The authors acknowledge the expert assistance of Rina Bollen, Lieve Gijsbers, Sylvia Van Hulle and Marie-Jeanne Jehoul (Study Coordinating Centre, University of Leuven, Leuven, Belgium).

\section{References}

1 London GM, Blacher J, Pannier B, Guerin AP, Marchais SJ, Safar ME. Arterial wave reflections and survival in end-stage renal failure. Hypertension $2001 ; 38: 434-438$.

2 Snieder H, Hayward CS, Perks U, Kelly RP, Kelly PJ, Spector TD. Heritability of central systolic pressure augmentation a twin study. Hypertension 2000; 35:574-579.

3 Danser AH, Schalekamp MA, Bax WA, van den Brink AM, Saxena PR, Riegger GA, et al. Angiotensin-converting enzyme in the human heart. Effect of the deletion/insertion polymorphism. Circulation 1995; 92:1387-1388

4 Weir MR, Dzau VJ. The renin-angiotensin-aldosterone system: a specific target for hypertension management. Am J Hypertens 1999; 12: 205S-213S.

5 Duprez D, De Buyzere M, Rietzschel ER, Clement DL. Aldosterone and vascular damage. Curr Hypertens Rep 2000; 2:327-334. 
6 Chen $\mathrm{CH}$, Nevo E, Fetics B, Pak PH, Yin FC, Maughan WL, et al. Estimation of central aortic pressure waveform by mathematical transformation of radial tonometry pressure. Validation of generalized transfer function. Circulation 1997; 95:1827-1836.

7 Staessen J, Bulpitt CJ, Fagard R, Joossens JV, Lijnen P, Amery A. Salt intake and blood pressure in the general population: a controlled intervention trial in two towns. J Hypertens 1988; 6:965-973.

8 Lindpaintner K, Pfeffer MA, Kreutz R, Stampfer MJ, Grodstein F, LaMotte $\mathrm{F}$, et al. A prospective evaluation of an angiotensin-converting-enzyme gene polymorphism and the risk of ischemic heart disease. N Engl J Med 1995; 332:706-711.

9 Brand E, Chatelain N, Mulatero P, Fery I, Curnow K, Jeunemaitre X, et al. Structural analysis and evaluation of the aldosterone synthase gene in hypertension. Hypertension 1998; 32:198-204.

10 Kleinbaum DG, Kupper LL, Muller KE. Applied regression analysis and other multivariate methods, 2nd edn. Boston, Massachusetts: MA Publishing Company; 1988, p. 585.

11 The SAS Institute. The GENMOD procedure. In: SAS Online Doc Version 7.1: SAS/STAT. Cary, North Carolina: The SAS Institute Inc.; 2000, pp. 1311-1411.

12 Abecasis GR, Cardon LR, Cookson WO. A general test of association for quantitative traits in nuclear families. Am J Hum Genet 2000; 66:279-292.

13 Allison DB. Transmission-disequilibrium tests for quantitative traits. Am J Hum Genet 1997; 60:676-690.

14 Brand E, Schorr U, Ringel J, Beige J, Distler A, Sharma AM. Aldosterone synthase gene (CYP11B2) C-344T polymorphism in Caucasians from the Berlin Salt-Sensitivity Trial (BeSST). J Hypertens 1999; 17: 1563-1567.

15 Tamaki S, Iwai N, Tsujita Y, Kinoshita M. Genetic polymorphism of CYP11B2 gene and hypertension in Japanese. Hypertension 1999; 33:266-270.

16 Rice DA, Mouw AR, Bogerd AM, Parker KL. A shared promoter element regulates the expression of three steroidogeneic enzymes. Mol Endocrinol 1999; 5:1552-1561.

17 Bassett MH, Zhang Y, Clyne C, White PC, Rainey WE. Differential regulation of aldosterone synthase and 11 beta-hydroxylase transcription by steroidogenic factor-1. J Mol Endocrinol 2002; 28:125-135.

18 White PC, Slutsker L. Haplotype analysis of CYP11B2. Endocr Res 1995; 21:437-442.

19 Clyne CD, Zhang Y, Slutsker L, Mathis JM, White PC, Rainey WE. Angiotensin II and potassium regulate human CYP11B2 transcription through common cis elements. Mol Endocrinol 1997; 11:638-649.

20 Sirianni R, Seely JB, Attia G, Stocco DM, Carr BR, Pezzi V, et al. Liver receptor homologue-1 is expressed in human steroidogenic tissues and activates transcription of genes encoding steroidogenic enzymes. $J$ Endocrinol 2002; 174:R13-R17.

21 Lijnen P, Petrov V. Induction of cardiac fibrosis by aldosterone. J Mol Cell Cardiol 2000; 32:865-879.

22 Pojoga L, Gautier S, Blanc H, Guyene TT, Poirier O, Cambien F, et al. Genetic determination of plasma aldosterone levels in essential hypertension. Am J Hypertens 1998; 11:856-860.

23 Paillard F, Chansel D, Brand E, Benetos A, Thomas F, Czekalski S, et al. Genotype-phenotype relationships for the renin-angiotensin-aldosterone system in a normal population. Hypertension 1999; 34:423-429.

24 Hautanena A, Lankinen L, Kupari M, Janne OA, Adlercreutz H, Nikkila H, et al. Associations between aldosterone synthase gene polymorphism and the adrenocortical function in males. J Intern Med 1998; 244 $11-18$.

25 Davies E, Holloway CD, Ingram MC, Inglis GC, Friel EC, Morrison C, et al. Aldosterone excretion rate and blood pressure in essential hypertension are related to polymorphic differences in the aldosterone synthase gene CYP11B2. Hypertension 1999; 33:703-707.

26 Kumar NN, Benjafield AV, Lin RC, Wang WY, Stowasser M, Morris BJ. Haplotype analysis of aldosterone synthase gene (CYP11B2) polymorphisms shows association with essential hypertension. J Hypertens 2003; 21:1331-1337.

27 O'Rourke MF, Staessen J, Vlachopoulos C, Duprez D, Plante GE. Clinical applications of arterial stiffness; Definitions and reference value. Am J Hypertens 2002; 15:426-444.

28 Blacher J, Amah G, Girerd X, Kheder A, Ben Mais H, London GM, et al. Association between increased plasma levels of aldosterone and decreased systemic arterial compliance in subjects with essential hypertension. Am J Hypertens 1997; 10:1326-1334.

29 Safar ME, Benetos A. Factors influencing arterial stiffness in systolic hypertension in the elderly: role of sodium and the renin-angiotensin system. Am J Hypertens 2003; 16:249-258.

30 Takeda Y, Yoneda T, Demura M, Miyamori I, Mabuchi H. Sodium-induced cardiac aldosterone synthesis causes cardiac hypertrophy. Endocrinology 2000; 141:1901-1904.

31 Takeda Y. Pathophysiological roles of vascular 11 beta-hydroxysteroid dehydrogenase and aldosterone. J Steroid Biochem Mol Biol 2003; 85:443-447.

32 Balkestein EJ, Staessen JA, Wang JG, Der Heijden-Spek JJ, Van Bortel $\mathrm{LM}$, Barlassina $\mathrm{C}$, et al. Carotid and femoral artery stiffness in relation to three candidate genes in a white population. Hypertension 2001; 38:1190-1197.

33 Benetos A, Gautier S, Ricard S, Topouchian J, Asmar R, Poirier O, et al. Influence of angiotensin-converting enzyme and angiotensin II type 1 receptor gene polymorphisms on aortic stiffness in normotensive and hypertensive patients. Circulation 1996; 94:698-703.

34 Luft FC, Fineberg NS, Sloan RS. Estimating dietary sodium intake in individuals receiving a randomly fluctuating intake. Hypertension 1982; 4:805-808.

\section{Appendix EPOGH Centres}

Belgium (Hechtel-Eksel): E. Balkestein, R. Bollen, H. Celis, S. Covens, E. Den Hond, L. De Pauw, P. Drent, D. Emelianov, R. Fagard, J. Gąsowski, L. Gijsbers, A. Hermans, T. Nawrot, L. Thijs, Y. Toremans, J.A. Staessen, S. Van Hulle, J.G. Wang, R. Wolfs.

Bulgaria (Sofia): C. Nachev, A. Postadjian, E.

Prokopova, E. Shipkovenska, K. Vitljanova.

Czech Republic (Pilzen): J. Filipovský, V. Svobodová, M. Tichá.

Ciech Republic (Prague): O. Beran, L. Golán, T. Grus, J. Peleška, Z. Marecková.

Italy (Padova): E. Casiglia, A. Pizzioli, V. Tikhonoff.

Poland (Cracow): K. Kawecka-Jaszcz, T. Grodzicki, K.

Stolarz, B. Wizner, A. Olszanecka, A. Adamkiewicz-

Piejko, W. Lubaszewski, J. Życzkowska, W.

Wojciechowska, M. Cwynar.

Romania (Bucharest): S. Babeanu, D. Jianu, C. Sandu,

D. State, M. Udrea.

Russian Federation (Novosibirsk): Y. Nikitin, S.

Malyutina, T. Kuznetsova, E. Pello, A. Ryabikov, M. Voevoda.

\section{Coordination and Committees}

Project Coordinator: J.A. Staessen.

Scientific Coordinator: K. Kawecka-Jaszcz.

Steering Committee: S. Babeanu (Romania), E. Casiglia

(Italy), J. Filipovský (Czech Republic), K. Kawecka-

Jaszcz (Poland), C. Nachev (Bulgaria), Y. Nikitin

(Russian Federation), J. Peleška (Czech Republic), J.A. Staessen (Belgium).

Data Management Committee: T. Kuznetsova, J.A.

Staessen, K. Stolarz, V. Tikhonoff, J.G. Wang.

Publication Committee: E. Casiglia, K. Kawecka-Jaszcz, Y. Nikitin.

Advisory Committee on Molecular Biology: G. Bianchi

(Milan), E. Brand (Berlin, Münster), H.A. Struijker-

Boudier (Maastricht).

EPOGH-EurNetGen Liaison: A. Dominiczak (Glasgow), J.A. Staessen (Leuven). 